\title{
POPs in a major conurbation in Turkey: ambient air concentrations, seasonal variation, inhalation and dermal exposure, and associated carcinogenic risks
}

\author{
Tugba Ugranli ${ }^{1,2}$ • Elif Gungormus ${ }^{1,2}$ • PInar Kavcar $^{2}$ • Eylem Demircioglu ${ }^{3}$. \\ Mustafa Odabasi $^{3}$ - Sait C. Sofuoglu ${ }^{1,2}$ - Gerhard Lammel ${ }^{4,5}$ - Aysun Sofuoglu ${ }^{2}$
}

Received: 1 May 2016 / Accepted: 29 July 2016 / Published online: 23 August 2016

(C) Springer-Verlag Berlin Heidelberg 2016

\begin{abstract}
Semi-volatile organic compounds were monitored over a whole year, by collection of gas and particle phases every sixth day at a suburban site in Izmir, Turkey. Annual mean concentrations of 32 polychlorinated biphenyls $\left(\sum_{32} \mathrm{PCBs}\right)$ and 14 polycyclic aromatic hydrocarbons $\left(\sum_{14} \mathrm{PAHs}\right)$ were $348 \mathrm{pg} / \mathrm{m}^{3}$ and $36 \mathrm{ng} / \mathrm{m}^{3}$, respectively, while it was $273 \mathrm{pg} / \mathrm{m}^{3}$ for endosulfan, the dominant compound among 23 organochlorine pesticides (OCPs). Monte Carlo simulation was applied to the USEPA exposure-risk models for the estimation of the population exposure and carcinogenic risk probability distributions for heating and non-heating periods. The estimated population risks associated with dermal contact and inhalation routes to $\sum_{32} \mathrm{PCBs}, \sum_{14} \mathrm{PAHs}$, and some of the targeted OCPs ( $\alpha$-hexachlorocyclohexane $(\alpha-$ $\mathrm{HCH}), \beta$-hexachlorocyclohexane $(\beta-\mathrm{HCH})$, heptachlor, heptachlor epoxide, $\alpha$-chlordane ( $\alpha$-CHL), $\gamma$-chlordane $(\gamma$-CHL),
\end{abstract}

Responsible editor: Constantini Samara

Electronic supplementary material The online version of this article (doi:10.1007/s11356-016-7350-5) contains supplementary material, which is available to authorized users.

Aysun Sofuoglu

aysunsofuoglu@iyte.edu.tr

1 Department of Environmental Engineering, İzmir Institute of Technology, Gülbahçe, 35430 Urla, İzmir, Turkey

2 Department of Chemical Engineering, İzmir Institute of Technology, Gülbahçe, 35430 Urla, İzmir, Turkey

3 Department of Environmental Engineering, Dokuz Eylul University, Tinaztepe Campus 35160, Buca, Izmir, Turkey

4 Multiphase Chemistry Department, Max Planck Institute for Chemistry, 55128 Mainz, Germany

5 Research Centre for Toxic Compounds in the Environment, Masaryk University, 62500 Brno, Czech Republic and $p, p^{\prime}$-dichlorodiphenyltrichloroethane $\left(p, p^{\prime}\right.$-DDT)) were in the ranges of $1.86 \times 10^{-16}-7.29 \times 10^{-9}$ and $1.38 \times 10^{-10}$ $4.07 \times 10^{-6}$, respectively. The inhalation 95 th percentile risks for $\sum_{32} \mathrm{PCBs}, \sum_{14} \mathrm{PAHs}$, and OCPs were about 6, 3, and 4-7 orders of magnitude higher than those of dermal route, respectively. The 95th percentile inhalation risk for $\sum_{32} \mathrm{PCBs}$ and OCPs in the non-heating period were 1.8- and 1.2-4.6 folds higher than in the heating period, respectively. In contrast, the 95th percentile risk levels for $\sum_{14} \mathrm{PAHs}$ in the heating period were 4.3 times greater than that of non-heating period for inhalation, respectively. While risk levels associated with exposure to PCBs and OCPs did not exceed the acceptable level of $1 \times 10^{-6}$, it was exceeded for $47 \%$ of the population associated with inhalation of PAHs with a maximum value of about $4 \times 10^{-6}$.

Keywords Persistent organic pollutants $\cdot$ PCBs - PAHs · OCPs $\cdot$ Exposure $\cdot$ Carcinogenic risk

\section{Introduction}

Semi-volatile organic compounds are considered as one of the significant groups of pollutants because of their wide presence in the environment. Especially the persistent ones, called as persistent organic pollutants (POPs), are of concern because of their characteristics, i.e., being bioaccumulative, capability of long-range atmospheric transport (LRAT) (Halse et al. 2011; Hogarth et al. 2012), low aqueous solubilities, and moderate vapor pressures (Castro-Jiménez et al. 2008; Wick et al. 2011). Although use of these chemicals was restricted/banned in the countries who signed the Stockholm Convention, they can still be detected in the environment because of their persistence, long-range transport, current use, and unintentional emissions (Pozo et al. 2006; MoEF 2010). 
The main sources of polychlorinated biphenyls (PCBs) and organochlorine pesticides (OCPs) are nowadays, decades after peak emissions, volatilization from contaminated sites, and long-range atmospheric transport (LRAT; Lammel and Stemmler 2012; Lohmann et al. 2007). Additional sources may be unintentional emissions from industrial applications and contaminated materials such as capacitors and transformers (Breivik et al. 2002). Polycyclic aromatic hydrocarbons (PAHs) can be released from natural and anthropogenic sources. Natural sources are volcanoes and forest fires, whereas the main anthropogenic sources are combustion of fossil fuels, e.g., traffic, residential heating, industry, and electricity production. After the emissions, partitioning processes take place in the environment. POP concentrations in air and partitioning between gas and particle phases are determined by many factors such as meteorology, primary and secondary emissions, deposition processes, oxidant availability, and their compartmental distribution (in turn dependent on physicochemical properties).

Exposure to POPs may have adverse health effects on the endocrine, immune, and nervous systems (Li et al. 2006), and may cause toxic, mutagenic, and carcinogenic effects (IARC 2013; He et al. 2014). Due to their effects on human health and the environment, production of most of these chemicals has been banned, and the Stockholm Convention (UNEP 2013) was signed to determine their levels and sources, and to prevent their use on a global scale. The Convention was signed and ratified by Turkey in 2001 and 2009, respectively. The national implementation encourages monitoring in air (MoEF 2010; MoEU 2015), which is not in place yet. Additionally, some of the PAHs (benzo[a]pyrene, benzo[b]fluoranthene, benzo[k]fluoranthene, and indeno[1,2,3-cd]pyrene) are targeted to be reduced back to their levels in the 1990s by the member states of the European Union in 2010 (EC 2001). The effectiveness of international chemical policy was indeed reflected as a decrease in POP levels in air (Dvorská et al. 2009; Pozo et al. 2012). POPs in air have been monitored in central and northern Europe, central parts of North America, as well as in the Arctic (e.g., Holoubek et al. 2007; Hung et al. 2010). Other understudied regions have recently been studied using passive air sampling, which comes with a factor of $\approx 2$ uncertainty (e.g., Pozo et al. 2009, 2012; Klánová et al. 2009; Halse et al. 2011), and also in Turkey (no results published; MoEU 2015). In some parts of the world, including Turkey, our knowledge of POP levels is very sparse and mainly relies on campaign-based (short-term) observations (Lohmann et al. 2007; Klánová et al. 2011). POPs were measured at polluted sites in Turkey reaching an average total (gas and particle phase) concentration of $3370 \mathrm{pg} / \mathrm{m}^{3}$ at an industrial site in summer for PCBs (Bozlaker et al. 2008), $1164 \mathrm{pg} / \mathrm{m}^{3}$ (chlorpyrifos) at an urban site in winter for OCPs (Odabasi et al. 2008), and $645 \mathrm{ng} / \mathrm{m}^{3}$ in winter (Esen et al. 2006) at an urban site for PAHs. POPs levels reported for the region are presented in Table 1.
Environmental human health risk assessment studies are limited for PCBs and OCPs compared to those for PAHs. Zhang et al. (2013) estimated inhalation carcinogenic risk for exposure to PCBs and OCPs in the Yangtze River Delta, China. The mean lifetime cancer risk for sum of some OCPS and $\sum_{6} \mathrm{PCBs}$ were $0.77 \times 10^{-6}, 0.83 \times 10^{-6}$, and $0.54 \times 10^{-6}$ for urban, urban-rural transition, and rural areas, respectively. Dermal and inhalation carcinogenic risks for PCBs reported for Catalonia, Spain, did not exceed $1 \times 10^{-5}$ (Vilavert et al. 2014). While no risk assessment has been conducted for PCBs and OCPs in Turkey, two studies are found for PAHs. Gaga et al. (2012) reported average inhalation risks for heating $\left(2.92 \times 10^{-3}\right)$ and non-heating periods $\left(1.15 \times 10^{-3}\right)$ in Kocaeli. Gungormus et al. (2014) estimated inhalation risk as $4.12 \times 10^{-5}$ and dermal risk as $1.63 \times 10^{-6}$ in Balikesir, a relatively small city.

The aim of this study was to determine ambient air PCB, OCP, and PAH concentrations throughout a full year using active air sampling, investigate their seasonal variation, and estimate associated carcinogenic risks for inhalation and dermal exposures in Izmir, the third largest metropolis in Turkey. This is the first such study and, so far, the most comprehensive POPs-related air monitoring activity in the country (MoEF 2010; MoEU 2015), which can establish a benchmark for assessing historical trends. Monte Carlo simulation was performed to determine the population carcinogenic risks, for which sensitivity and uncertainty analyses were also conducted.

\section{Materials and methods}

\section{Sampling, sample processing, and analysis}

Air samples were collected at Kaynaklar Campus of Dokuz Eylul University $\left(38^{\circ} 22^{\prime} \mathrm{N}, 27^{\circ} 12^{\prime} \mathrm{E}\right)$ located in a suburban area in Izmir. Izmir is the third largest city in Turkey with a population of 4,061,074 (TUIK 2013). Daytime (8:00 a.m. to sunset) sampling was conducted once every 6 days from May 2003 to April 2004. A total of 51 samples, 30 in the non-heating period (April to September) and 21 in the heating period (October to March), were collected. Meteorological data were obtained from a 10-m-high tower located at the sampling site. The average temperature was 23.6 and $12.2{ }^{\circ} \mathrm{C}$ for non-heating and heating periods, respectively.

Air samples were collected using a modified high-volume sampler model GPS-11 (Thermo-Andersen Inc.). Particles (total suspended particles) were collected on 10.5-cm-diameter quartz filters and the gas-phase compounds were collected in a modified cartridge containing $30 \mathrm{~g}$ XAD-2 resin placed between layers of polyurethane foam (PUF) (6-cm diameter, 5$\mathrm{cm}$ length each) at an average sampling flow rate of $0.262 \mathrm{~m}^{3} /$ $\min$. The average sampling volume was $173 \pm 44 \mathrm{~m}^{3}$ while the 
Table 1 Overview of the gas-phase mean concentrations observed in near-ground air in the region (PAHs: ng $/ \mathrm{m}^{3}$, all other: $\mathrm{pg} / \mathrm{m}^{3}$ ). Limited number of individual substances included for the sake of comparability

\begin{tabular}{|c|c|c|c|c|c|c|}
\hline Study & Sampling Time & Sampling Site & $\mathrm{\Sigma PAH}_{5}{ }^{\mathrm{a}}$ & $\Sigma \mathrm{PCB}_{7}{ }^{\mathrm{b}}$ & $\Sigma \mathrm{HCH}^{\mathrm{c}}$ & EDDTs $^{\mathrm{d}}$ \\
\hline \multicolumn{7}{|l|}{ Rural, residential } \\
\hline Lammel et al. 2015 & Summer 2012 & Thessaloniki area, residential site & $2.33-3.64$ & $26.7-47.5$ & $9.3-10.4$ & $8.4-51 / 0.56-1.12$ \\
\hline Lammel et al. 2015 & Summer 2012 & Athens/Greece, suburban site & 0.25 & 50.2 & 9.7 & 4.7 \\
\hline Lammel et al. 2015 & Summer 2012 & C Greece, rural site & 0.58 & 9.0 & 4.8 & 7.0 \\
\hline Lammel et al. 2015 & Summer 2012 & NW Turkey, semi-residential site & 0.23 & 25.6 & 5.7 & 7.9 \\
\hline Lammel et al. 2015 & Summer 2012 & $\begin{array}{l}\text { Gulbahce/Izmir/W Turkey, } \\
\text { rural/coastal site }\end{array}$ & 0.27 & 55.3 & 13.8 & 12.8 \\
\hline Yolsal et al. 2014 & Whole year 2008-09 & NW Turkey, rural and coastal sites & & 80 & & \\
\hline Birgül and Taşdemir 2011 & Whole year 2008-09 & NW Turkey, semi-rural site & & 74 & & \\
\hline Halse et al. 2011 & Summer 2006 & Aliartos/C Greece, rural site & 23.7 & 13.6 & 54.0 & 228 \\
\hline Stafilov et al. 2011 & Summer 2007 & Macedonia, 2 rural sites & & $24-174$ & $101-182$ & $36-126$ \\
\hline Terzi and Samara 2004 & Whole year 2000-01 & W Greece, 2 rural sites & $2.9-13.8$ & & & \\
\hline This study & $\begin{array}{l}\text { Whole year 2003-04 } \\
\text { Heating/non-heating season }\end{array}$ & Izmir, suburban site & $37.6 / 13.9^{\mathrm{e}}$ & $49.4 / 107$ & $17.1 / 43.7$ & $33.9 / 55.3$ \\
\hline \multicolumn{7}{|l|}{ Urban, industrial } \\
\hline Lammel et al. 2015 & Summer 2012 & Thessaloniki area, urban site & 2.38 & 85.7 & 14.9 & $42.5 / 6.96$ \\
\hline Odabasi et al. 2015 & Fall 2011 & Aliaga/ Izmir/W Turkey & $\begin{array}{l}24.6-553 \\
(105 \pm 105)\end{array}$ & $\begin{array}{l}65.7-2011 \\
(672 \pm 524)\end{array}$ & & \\
\hline Birgül et al. 2011; Yolsal et al. 2014 & Whole year 2008-09 & Bursa/NW Turkey & $117^{\mathrm{f}}$ & 67 & & \\
\hline Kaya et al. 2012 & All seasons 2009-10 & Aliaga/ Izmir/W Turkey & 78 & 2560 & & \\
\hline Akyüz and Çabuk 2010 & Winter/summer 2007-08 & Zonguldak/N Turkey & $260 / 21$ & & & \\
\hline Ozcan and Aydin 2009 & Whole year 2006-07 & Konya/S Turkey & 93 & 78 & 520 & 130 \\
\hline Pozo et al. 2009 & Winter/summer 2005 & Izmir/W Turkey & & $644 / 287$ & $29 / 48$ & $51 / 60$ \\
\hline Vasilakos et al. 2007 & June and November 2003 & Athens/Greece, 2 sites in suburban area & $17.5-20.1^{\mathrm{f}}$ & & & \\
\hline Tașdemir and Esen 2007 & All seasons 2004-05 & Bursa/NW Turkey & 20 & & & \\
\hline Terzi and Samara 2004 & Whole year 2000-01 & W Greece, urban site & $21.7^{\mathrm{f}}$ & & & \\
\hline
\end{tabular}

${ }^{\mathrm{a}}$ sum of ACE, FLN, PHE, FLT, and PYR

${ }^{\mathrm{b}} \mathrm{PCB}-28,-52,-101,-118,-138,-153,-180$

${ }^{\mathrm{c}}$ sum of $\alpha$ - and $\gamma-\mathrm{HCH}$

${ }^{\mathrm{d}}$ sum of DDT and DDE isomers

${ }^{\mathrm{e}}$ without ACE

${ }^{f}$ without ACE, FLN

average sampling time was $11 \pm 1 \mathrm{~h}$. Before sampling, quartz filters were conditioned at $450{ }^{\circ} \mathrm{C}$ and cooled down to room temperature in a desiccator. Soxhlet extraction was applied for cleaning of the PUF cartridges with acetone/hexane mixture (1:1) for $12 \mathrm{~h}$, and then the cartridges were covered in aluminum foil and dried at $70{ }^{\circ} \mathrm{C}$, and replaced into a glass container with a Teflon lid until sampling. Gas and particle samples were extracted by soxhlet extraction for $12 \mathrm{~h}$ with dichloromethane (DCM)/petroleum ether (PE) (1:4). Prior to extraction, PCB (PCB-14, 65, and 166; each $10.5 \mathrm{ng} /$ sample) and PAH (naphthalene-d8, acenaphthene-d10, phenanthrene-d10, chrysene-d12, and perylene-d12; each $8000 \mathrm{ng} /$ sample) surrogate standards were spiked to the samples to determine the recovery efficiencies. Volumes of extracts were reduced to $2 \mathrm{ml}$ and solvent was exchanged to hexane using a rotary evaporator. Then, samples were introduced into columns packed with $3 \mathrm{~g}$ of silicic acid (deactivated with $3 \%$ deionized water) and $2 \mathrm{~g}$ of alumina (deactivated with $6 \%$ deionized water) which were pre-washed with $20 \mathrm{ml}$ DCM followed by $20 \mathrm{ml}$ PE. Samples were eluted with $25 \mathrm{ml} \mathrm{PE}$ (fraction 1 containing PCBs) followed by $25 \mathrm{ml}$ DCM (fraction 2 containing PAHs and OCPs). Finally, solvent was changed into hexane and final volume was reduced to $1 \mathrm{ml}$ with a gentle $\mathrm{N}_{2}$ stream. All samples were analyzed for PAHs, PCBs, and OCPs in separate runs for each POP group with an Agilent $6890 \mathrm{~N}$ gas chromatograph (GC) equipped with a mass selective detector (Agilent 5973 inert MSD). PAHs and PCBs were analyzed using electron impact ionization (EI) while negative chemical ionization (NCI) was used for OCPs. The capillary column used was HP5-MS (30 m, $0.25 \mathrm{~mm}, 0.25 \mu \mathrm{m}$ ). Helium was the carrier gas (at a flow rate of $1.5 \mathrm{ml} / \mathrm{min}$ for PAHs and PCBs and $1.0 \mathrm{ml} / \mathrm{min}$ for OCPs) and high purity methane was the reagent gas for NCI. For PAHs, the initial oven temperature was held at $50{ }^{\circ} \mathrm{C}$ for $1 \mathrm{~min}$ and raised to $200{ }^{\circ} \mathrm{C}$ at $25{ }^{\circ} \mathrm{C} / \mathrm{min}$, to $300{ }^{\circ} \mathrm{C}$ at $8{ }^{\circ} \mathrm{C} /$ $\mathrm{min}$, and was held for $5.5 \mathrm{~min}$. The injector, ion source, and quadrupole temperatures were 295,300 , and $180^{\circ} \mathrm{C}$, respectively. For PCBs, the same temperature program was used except the final hold time was $3 \mathrm{~min}$. The injector, ion source, and quadrupole temperatures were 250,230 , and $150^{\circ} \mathrm{C}$, respectively. Prior to analysis, OCP samples were spiked with internal standard (BDE-77,3,3',4,4'-tetrabromodiphenyl ether, 
$20 \mathrm{ng} / \mathrm{sample}$ ). The initial oven temperature was held at $50^{\circ} \mathrm{C}$ for $1 \mathrm{~min}$, was raised to $100{ }^{\circ} \mathrm{C}$ at $25{ }^{\circ} \mathrm{C} / \mathrm{min}$, to $260{ }^{\circ} \mathrm{C}$ at $5^{\circ} \mathrm{C} / \mathrm{min}$, to $300^{\circ} \mathrm{C}$ at $10^{\circ} \mathrm{C} / \mathrm{min}$, and was held for $2 \mathrm{~min}$. The injector, ion source, and quadrupole temperatures were 250 , 150 , and $150{ }^{\circ} \mathrm{C}$, respectively. Compounds were identified based on their retention times and target and qualifier ions, and were quantified using the internal standard calibration procedure. Additional details can be found elsewhere for PCBs, OCPs (Sofuoglu et al. 2004; Odabasi et al. 2008), and PAHs (Demircioglu et al. 2011). Concentrations of 32 PCBs (PCB-17, PCB-18, PCB-28, PCB-31, PCB-33, PCB44, PCB-49, PCB-52, PCB-70, PCB-74, РCB-82, РCB-87, PCB-95, PCB-99, PCB-101, PCB-105, PCB-110, PCB-118, PCB-128, PCB-132, PCB-138, PCB-149, PCB-151, PCB153, PCB-158, PCB-170, PCB-171, PCB-177, PCB-180, PCB-183, PCB-187, PCB-199); 23 OCPs (those that were legally in use as pesticides and their metabolites: chlorpyripos (CHLPYR), endosulfan I (ESLF I), endosulfan II (ESLF II), endosulfan sulfate (ESLF SUL) and those that were banned around the 1980s in Turkey: methoxychlor (MEOCL), heptachlor (HEPCHL), heptachlor epoxide (HEP EPOX), aldrin (ALD), $\alpha$-chlordane ( $\alpha$-CHL), $\gamma$-chlordane $(\gamma$-CHL), $c$ nonachlor ( $c$-NONA), $t$-nonachlor ( $t$-NONA), endrin aldehyde (END AL), endrin ketone (END KET), endrin (END), dieldrin (DIELD), $p, p^{\prime}$-dichlorodiphenyldichloroethylene ( $p, p^{\prime}$-DDE), $p, p^{\prime}$-dichlorodiphenyltrichloroethane ( $p, p^{\prime}$-DDT), $p, p^{\prime}$-dichlorodiphenyldichloroethane ( $p, p^{\prime}$-DDD), $\alpha$-hexachlorocyclohexane $(\alpha$-HCH), $\beta$-hexachlorocyclohexane $(\beta$-HCH), $\gamma$-hexachlorocyclohexane $(\gamma$ $\mathrm{HCH}), \delta$-hexachlorocyclohexane $(\delta$-HCH$))$; and 14 PAHs (fluorene (Flu), phenanthrene (PHE), anthracene (Ant), carbazole (Carb), fluoranthene(FL), pyrene (Pyr), benzo[a]anthracene (BaA), chrysene (Chry), benzo[b]flouranthene $(\mathrm{BbF})$, benzo $[k]$ fluoranthene $(\mathrm{BkF})$, benzo $[a]$ pyrene $(\mathrm{BaP})$, indeno $[1,2,3-c d]$ pyrene (Ind), dibenzo $[a, h]$ anthracene (DahA), and benzo[ghi]pyrene (BghiP)) were quantified.

Average recoveries (determined from the response ratios from calibration and sample analysis runs) of PCB surrogate standards including filters and PUFs were $97 \pm 17 \%$ for PCB$14,107 \pm 18 \%$ for PCB-65, and $93 \pm 31 \%$ for PCB-166 $(n=102)$. The recoveries of target compounds were also determined externally by matrix spike experiments. Average external recoveries of targeted $\mathrm{PCB}$ congeners ( $n=12$ replicates) were in the range of $69 \pm 15 \%$ (PCB-18) and $115 \pm 5 \%$ (PCB$49)$ with a general exceedance of $85 \%$. Average external recovery of OCPs ( $n=6$ replicates) was $85 \pm 21 \%$ with a range of $40 \pm 11 \%$ (endosulfan II) and $128 \pm 22 \%$ (endosulfan sulfate), which were generally higher than $70 \%$. Since the recoveries were generally high, sample amounts were not corrected for external recoveries. Average recoveries of PAH surrogate standards were found as $68 \pm 14 \%$ for PHE-d $\mathrm{C}_{12}$, $82 \pm 14 \%$ for CHR-d $\mathrm{d}_{12}$, and $77 \pm 19 \%$ for perylene- $\mathrm{d}_{12}$ $(n=102)$. The spike recoveries $(n=6$ replicates $)$ of the targeted PAH species were found between $88 \pm 22 \%$ (DahA) and $121 \pm 6 \%$ IcdP with the average of $107 \pm 16 \%$. Instrumental detection limits (IDLs) were determined from linear extrapolation, based on the lowest standard in calibration curve and using the area of a peak having a signal/noise ratio of 3 . For $1-\mu$ injection, the quantifiable amounts were $0.15,0.10$, and $0.01-0.35 \mathrm{pg}$ for PAHs, PCBs, and OCPs, respectively. Blank filters and cartridges columns ( $n=6$ for each) were also analyzed to determine if there was contamination during sampling and sample preparation. Method detection limit (MDL, ng) was defined as the mean blank mass plus three standard deviations $(\mathrm{MDL}=$ mean blank value +3 SD). IDLs were used for the compounds that were not detected in blanks. Method detection limits were also expressed in terms of air concentrations by dividing them by the average sampling volume. Gas-phase MDLs ranged between $0.01(\mathrm{BaP})$ and $0.9(\mathrm{PHE}) \mathrm{ng} / \mathrm{m}^{3}, 0.6(\mathrm{PCB}-70)$ and 5.4 (PCB-18) $\mathrm{pg} / \mathrm{m}^{3}$, and $0.1(\alpha-\mathrm{CHL})$ and $7.2\left(p, p^{\prime}-\mathrm{DDE}\right) \mathrm{pg} / \mathrm{m}^{3}$ for PAHs, PCBs, and OCPs, respectively. Particle-phase MDLs ranged between $0.01(\mathrm{BaA})$ and $0.5(\mathrm{PHE}) \mathrm{ng} / \mathrm{m}^{3}$, 0.6 (PCB-70) and 3.3 (PCB-18) pg/m $\mathrm{m}^{3}$, and $0.1(\alpha-\mathrm{CHL})$ and $5.0\left(p, p^{\prime}\right.$-DDE) $\mathrm{pg} / \mathrm{m}^{3}$ for PAHs, PCBs, and OCPs, respectively. Average analyte amounts in blanks were generally $<10 \%$ of the amounts found in samples. Sample quantities exceeding the MDLs were quantified and blank-corrected by subtracting the mean blank amount from the sample amount. Additional QA/QC information can be found in Sofuoglu et al. (2004), Odabasi et al. (2008), and Demircioglu et al. (2011).

\section{Exposure and risk assessment}

Exposure assessment was conducted for the routes of inhalation and dermal contact, and associated health risks were assessed. Chronic daily intake (CDI) was used as the measure of exposure for PCB, OCP, and PAH compounds. Equations 1 and 2 were used for inhalation and dermal exposures, respectively (USEPA 1992a).

$$
\sum_{j=1}^{J} \mathrm{iCDI}=\frac{C_{i} \times I R \times E D \times E F}{B W \times A T}
$$

where iCDI is the inhalation chronic daily intake ( $\mathrm{pg} / \mathrm{kg} /$ day for PCBs and OCPs, ng/kg/day for PAHs); $C$ is the pollutant concentration ( $\mathrm{pg} / \mathrm{m}^{3}$ for PCBs and OCPs, $\mathrm{ng} / \mathrm{m}^{3}$ for PAHs); IR is the average daily intake rate of air $\left(\mathrm{m}^{3} /\right.$ day); ED is the exposure duration and equal to 70 years for lifetime exposure assessment; EF is the exposure frequency (180 days/year for heating and non-heating periods), BW is the body weight ( $\mathrm{kg})$, AT is the averaging time (70 years), $i$ is the compound, and $j$ is the heating and non-heating periods $(j=2)$. In this case, indoor pollutant concentrations were assumed as equal to those 
measured outdoors. PAH concentrations were converted to $\mathrm{BaP}$ equivalent $\left(\mathrm{BaP}_{\mathrm{eq}}\right)$ concentrations by using toxic equivalency factor (TEF) values given in Supplementary Material (SM) Table S1.

$$
\sum_{j=1}^{J} \mathrm{dCDI}=\frac{C_{p i} \times K p \times S A \times E D \times E F}{B W \times A T}
$$

where dCDI is the dermal chronic daily intake ( $\mathrm{pg} / \mathrm{kg}$ /day for PCBs and OCPs, ng/kg/day for PAHs); $C_{p}$ is the particlephase pollutant concentration $\left(\mathrm{pg} / \mathrm{m}^{3}\right.$ for PCBs and OCPs, $\mathrm{ng} / \mathrm{m}^{3}$ for PAHs); $K p$ is the permeability coefficient ( $\mathrm{m} /$ day); and SA is the body surface area exposed to the contaminant $\left(\mathrm{m}^{2}\right) . K p$ values for PCBs, OCPs, and PAHs were obtained from RAIS (2013). SA was calculated using Eq. 3 which relates the body weight to the body surface area (Livingston and Lee 2001), where SA is in square meters and BW is in kilograms.

$\mathrm{SA}=0.1173 \times \mathrm{BW}^{0.6466}$

Since exposed surface area changes depending on the seasons, hands (2.7 \% of SA) and head (4.0\% of SA) were considered for the heating period while arms (12.6\% SA) were added for the non-heating period.

Lifetime cancer risk associated with inhalation and dermal exposures to OCPs, $\Sigma_{14} \mathrm{PAHs}$, dioxin-like PCBs, and nondioxin-like PCBs were calculated using Eq. 4. Dioxin-like PCBs were considered separately because they are attributed with potency of dioxin which can be converted with the use of a TEF (i.e., 0.00003 (USEPA 2010) for the only detected dioxin-like congener PCB-118 among the PCBs that exposure could be estimated). Then, the total carcinogenic risk for PCBs was calculated by summation of risk values of dioxinlike PCB and non-dioxin-like PCBs.

$R=\mathrm{CDI} \times \mathrm{SF}$

where $R$ is the estimated lifetime cancer risk, $\mathrm{CDI}$ is the chronic daily intake ( $\mathrm{pg} / \mathrm{kg} /$ day for PCBs and OCPs, $n g / \mathrm{kg} /$ day for $\mathrm{PAHs}$ ), and SF is the slope factor of the subject pollutant ( $1 /(\mathrm{pg} / \mathrm{kg} /$ day) for PCBs and OCPs, and $1 /(\mathrm{ng} / \mathrm{kg} /$ day) for PAHs).

There was no available dermal slope factor for OCPs. However, it can be estimated by dividing oral SF by gastrointestinal adsorption factor (USEPA 1992b) which can be assumed as one conservatively for all OCPs (RAIS 2013). All SF values were taken from IRIS (2015) except for dioxin and dermal SF of $\gamma$-HCH obtained from USEPA (1997), and inhalation SF values of $\mathrm{BaP}$ and $\gamma-\mathrm{HCH}$ taken from CalEPA (2005). All data used in the calculations are given in SM, Table S2.

\section{Statistical methods}

Risk assessment was performed for compounds that were detected $\geq 50 \%$ of the samples, for which the missing data were generated by fitting a distribution to the measured concentrations (Helsel 1990). Detection frequencies are shown in SM, Table S3. Most of the data were below detection limit (BDL) for particle phase dioxin-like PCB-118 (MDL $=0.6 \mathrm{pg} / \mathrm{m}^{3}$ for both gas and particle phases). However, due to its presence in the gas phase, we opted to include this compound in the assessment. Therefore, half of instrumental detection limit was assigned as concentration for these days. The average concentration was used for health risk assessment instead of fitting a distribution since it would have been distorted.

Monte Carlo Simulation was conducted using Crystal Ball (v 4.0e) software. Monte Carlo is a simulation program acquiring a probabilistic approximation by using statistical sampling techniques to the output of a mathematical equation or a model. The best probability distribution to describe input and output variables was determined based on the KolmogorovSmirnov and Anderson-Darling tests. Distribution of body weight was taken from Kavcar et al. (2006) to represent Izmir population (lognormal distribution; mean $=65.56$, standard deviation $=13.02 \mathrm{~kg}$ ). Inhalation rate was assumed to have a uniform distribution with minimum and maximum values 0.21 and $0.74 \mathrm{~m}^{3} / \mathrm{h}$, respectively, as reported by Gephart et al. (1994). For each simulation, 10,000 trials were performed, and this many forecasts were obtained to fit the population distribution. Seasonal differences were tested using Mann-Whitney non-parametric hypothesis test using a significance level of 0.05 . Kolmogorov-Smirnov test was also applied for confirmation. The results were in agreement with each other and $p$ values obtained from Mann-Whitney tests are presented.

\section{Results and discussion}

\section{Ambient air concentrations}

POP concentrations in this section are presented as total concentrations (gas + particle - phase) unless specified otherwise.

\section{$P C B S$}

The mean, median, and 95th percentile concentrations of $\sum_{32} \mathrm{PCBs}$ were 348,276 , and $861 \mathrm{pg} / \mathrm{m}^{3}$, respectively. There was a seasonal variation in the concentrations of homolog groups of PCBs as shown in Fig. 1. The mean, median, and 95th percentile of gas-phase $\sum_{32} \mathrm{PCB}$ concentrations in the non-heating period were 377,275 , and $1521 \mathrm{pg} / \mathrm{m}^{3}$, respectively, whereas lower concentrations were measured (184, 163 , and $567 \mathrm{pg} / \mathrm{m}^{3}$, respectively) in the heating period 
Fig. 1 Seasonal variation in the average PCB concentrations. a Gas phase in non-heating period. b Particle phase in non-heating period. $\mathbf{c}$ Gas phase in heating period. d Particle-phase in heating period (error bars indicate one standard deviation) a

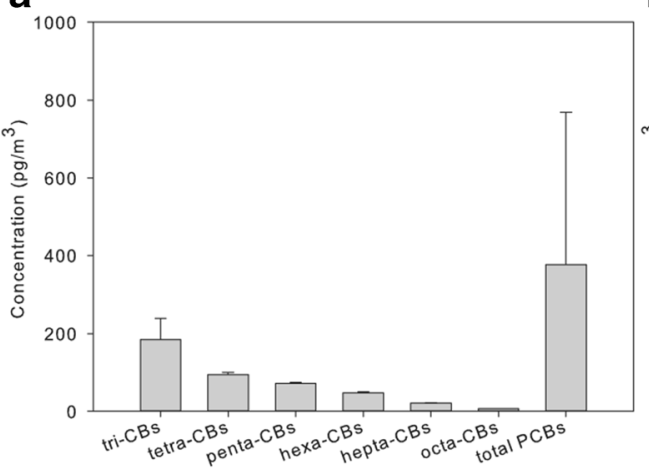

b

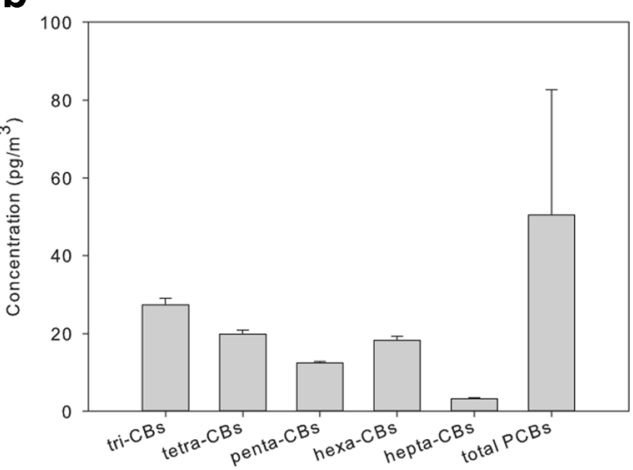

C

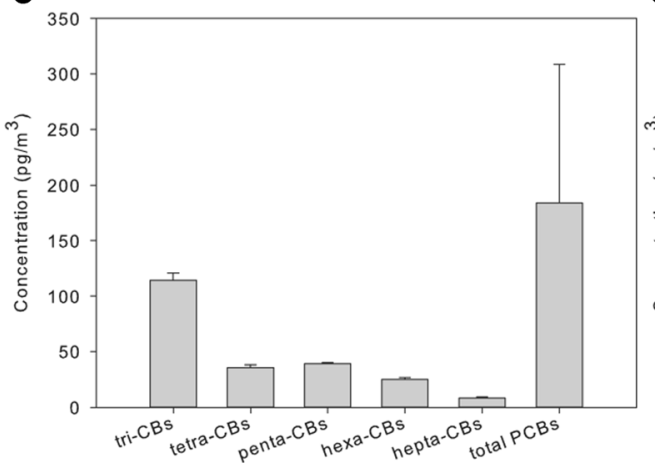

d

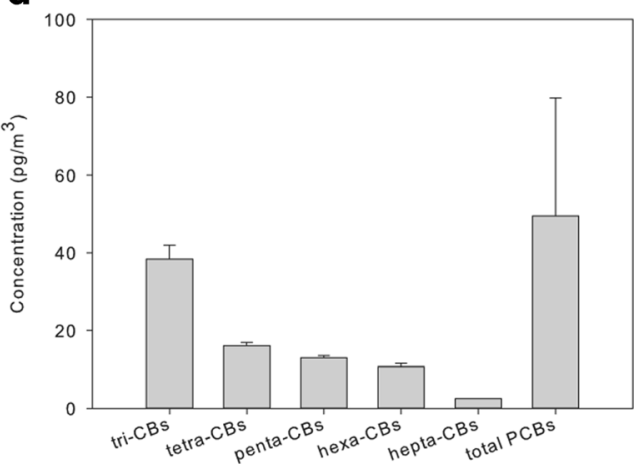

( $p=0.001)$. Particle-phase concentrations in the non-heating period was similar to the measured concentrations in the heating period ( $p=0.74$ ) (Fig. 1). Tri-CBs dominated the homolog pattern, in agreement with those reported in the literature (Stern et al. 1997; Choi et al. 2008). Fractions of tri-, tetra-, penta, hexa-, hepta-, and octa-CBs in $\sum_{32} \mathrm{PCBs}$ were $52.6,23.2,14.2,8.1,1.7$, and $0.2 \%$, respectively. PCB concentrations in the non-heating period were generally greater than the heating period concentrations probably because increasing temperature increases volatilization from contaminated terrestrial surfaces (Sofuoglu et al. 2001). In general, $86 \%$ of the detected PCBs were in the gas phase. Cetin et al. (2007) measured the average $\sum_{36} \mathrm{PCB}$ concentrations as 847 and $314 \mathrm{pg} / \mathrm{m}^{3}$ in March-April 2005 and June 2005, respectively, on the shore of Aegean Sea in urban Izmir. The average heating period- $\sum_{32} \mathrm{PCBs}$ concentration measured in this study is much lower than the winter concentration reported by Cetin et al. (2007) while the opposite is observed for the non-heating period compared to the reported summer concentration. Higher concentrations measured in winter were explained by the southerly winds carrying pollutants from the industrial area located SW of the urban area. The ferrous scrap processing steel plants with electric furnaces were found to be hot spots for POPs in the area (Bozlaker et al. 2009). Aliaga industrial area is located north of the sampling site of the present study. Therefore, northerly winds may carry POPs from the Aliaga industrial region where reported mean concentrations were as high as $8727 \mathrm{pg} / \mathrm{m}^{3}$ (Kaya et al. 2012).
OCPS

Seasonal variation in individual OCPs in gas and particle phases are shown in Fig. 2. The dominating OCP was endosulfan I (52\% of the total OCPs) with mean, median, and $95 \%$ percentile concentrations of $273,96.6$, and $1155 \mathrm{pg} / \mathrm{m}^{3}$, respectively. The compound having the lowest level was $t$-nonachlor $(0.14 \%$ of the total OCPs) with the mean, median, and $95 \%$ percentile concentrations of $0.75,0.27$, and $8.08 \mathrm{pg} / \mathrm{m}^{3}$, respectively. Among the remaining OCPs, chlorpyrifos, endosulfan I, and endosulfan II had higher concentrations probably because these compounds were legally in use during the sampling period. This is also reflected in high endosulfan levels in biota in Turkey (MoEF 2010). The mean concentration ratios of $\alpha-\mathrm{CHL} / \gamma-\mathrm{CHL}$ and $\alpha$ $\mathrm{HCH} / \gamma-\mathrm{HCH}$ were 1.96 and 1.07 , respectively, suggesting past emissions (Haugen et al. 1998). The respective ratios of 0.83 and 0.80 were reported for the Aliaga industrial region, also indicating past use (Bozlaker et al. 2008). Gas-phase average concentrations of OCPs in the non-heating period were in the range of 1.10 (c-nonachlor) to $26.4 \mathrm{pg} / \mathrm{m}^{3}$ (endosulfan I), and of BDL to $42.5 \mathrm{pg} / \mathrm{m}^{3}$ (endosulfan I) in the heating period. Gaseous phase concentrations of heptachlor and $p, p^{\prime}$-DDE in the heating period were similar to those measured in the non-heating period ( $p=0.965$ and $p=0.314$, respectively), whereas all the others were significantly different. Particle-phase average concentrations of OCPs were in the range of BDL to $25.4 \mathrm{pg} / \mathrm{m}^{3}$ (endosulfan II) in the non-heating period and of BDL to $16.8 \mathrm{pg} / \mathrm{m}^{3}$ (chlorpyrifos) in the heating period. The levels of $p, p^{\prime}$-DDT, 


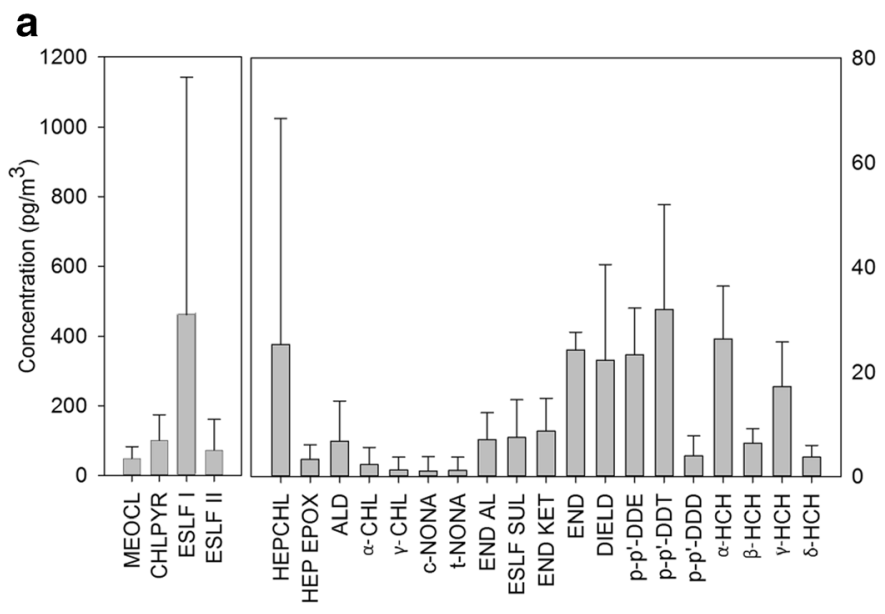

b

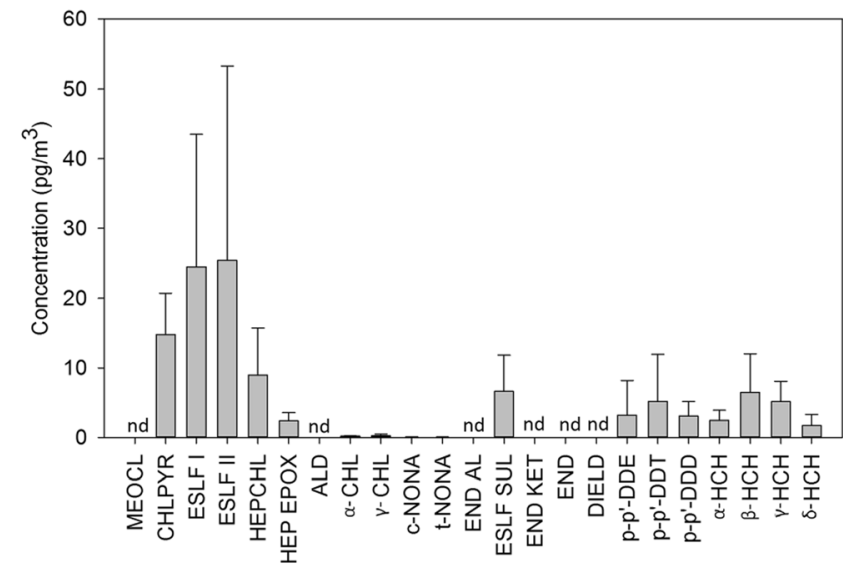

d

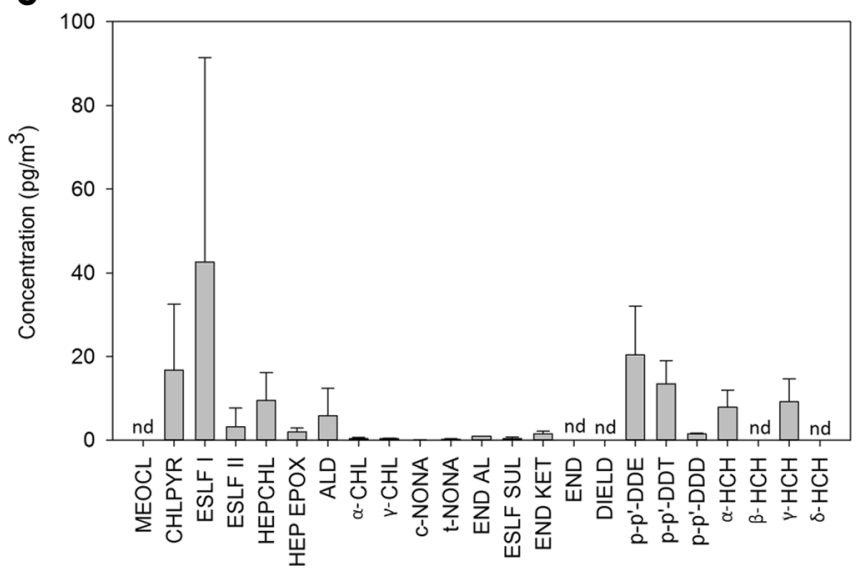

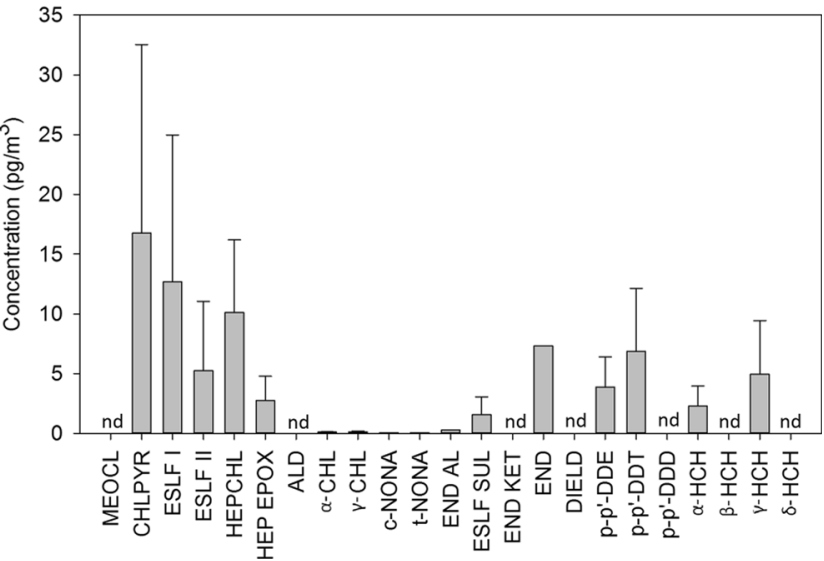

Fig. 2 Seasonal variation in the average OCP concentrations a Gas phase in non-heating period. b Particle phase in non-heating period. $\mathbf{c}$ Gas phase in heating period. $\mathbf{d}$ Particle phase in heating period (error bars indicate one standard deviation)

endosulfan II, $p, p^{\prime}$-DDE, and endosulfan sulfate in the nonheating period were significantly higher than those in the heating period $(p=0.035, p=0.001, p=0.033$, and $p<0.0001$, respectively). The remaining OCPs were either not detected in one of the periods or the difference was not significant. Higher particlephase concentrations of some OCPs in winter were reported by Yenisoy-Karakas et al. (2012) with some exceptions in Bolu in relation to the difference in the winter- and summer-dominant wind sectors. High particle-phase levels in winter may be related to transport of particles to the sampling site with accumulated chemicals on particle surfaces by dominant winds. Higher levels of gas-phase $\alpha-\mathrm{HCH}$ were reported as $71.9 \mathrm{pg} / \mathrm{m}^{3}$ for summer and $17.1 \mathrm{pg} / \mathrm{m}^{3}$ for winter than those of particle phase ( 0.6 for summer and $0.2 \mathrm{pg} / \mathrm{m}^{3}$ for winter) in Aliaga industrial region (Odabasi and Cetin 2012). Heptachlor epoxide, $\alpha$-CHL, and $\gamma$-CHL concentrations were similar to the concentrations observed in the present study. Particle-phase $p, p^{\prime}$-DDT concentrations measured in this study were one order of magnitude higher in the non-heating period and 3.6 times higher in heating period compared to Aliaga. All $\gamma-\mathrm{HCH}$ concentrations were reported to be higher in Aliaga compared to this study except for summer.
PAHS

Concentrations of PAHs are briefly presented here because they were previously discussed in detail elsewhere (Demircioglu et al. 2011). The mean concentrations of targeted 14 PAH compounds in gas and particle phases in the two periods are shown in Fig. 3. Annual mean concentration of $\sum_{14} \mathrm{PAHs}$ was $35.7 \mathrm{ng} / \mathrm{m}^{3}$. Dominant compounds in gas phase were PHE and Flu, followed by FL and Pyr in both seasons. The most abundant compound in particle phase was PHE in the non-heating period; FL, Chry, PHE, and Pyr in the heating period. Gas- and particle-phase PAH concentrations were significantly lower in non-heating period but the contribution of gas phase to $\sum_{14} \mathrm{PAHs}$ (gas + particle) were 62 and $71 \%$ in the heating and non-heating periods, respectively, for which the difference was significant $(p<0.0001)$. The higher contribution may be attributed to the effect of higher temperatures increasing the volatilization from contaminated surfaces, shifting the gas-particle partitioning to gas phase. Ambient air standard in Turkey for annual average $\mathrm{PM}_{10}$-bound $\mathrm{BaP}$ concentration was published to come into effect as $1 \mathrm{ng} / \mathrm{m}^{3}$ in January 2020 (Official Gazette, 2008). The annual average 
a

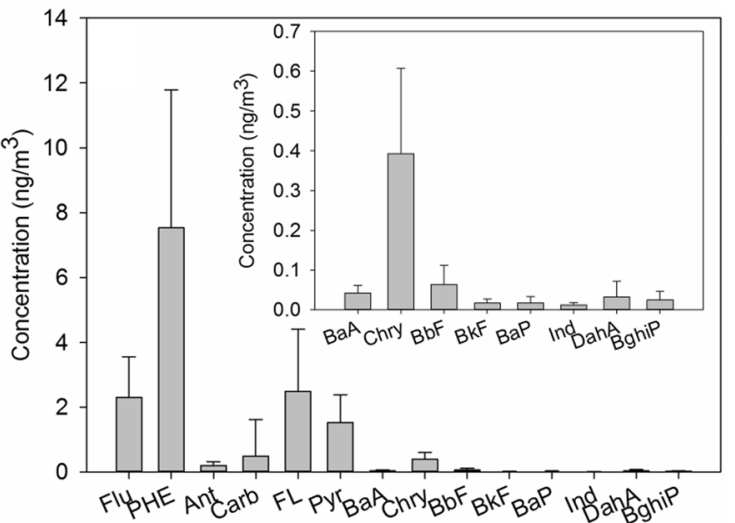

C

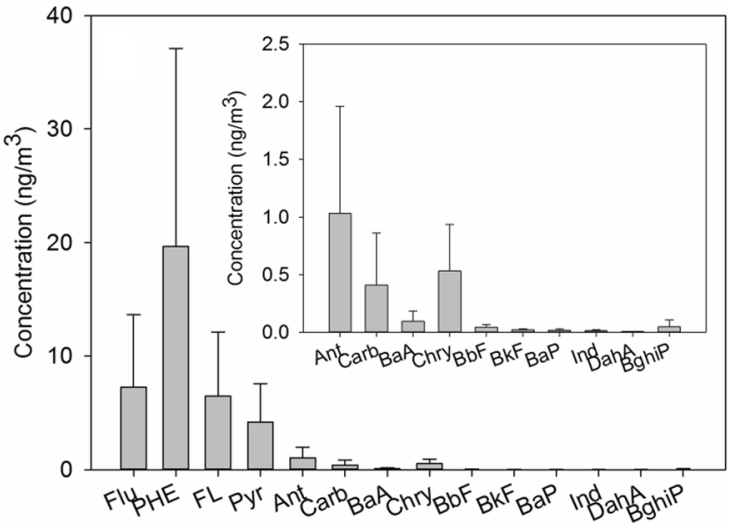

b

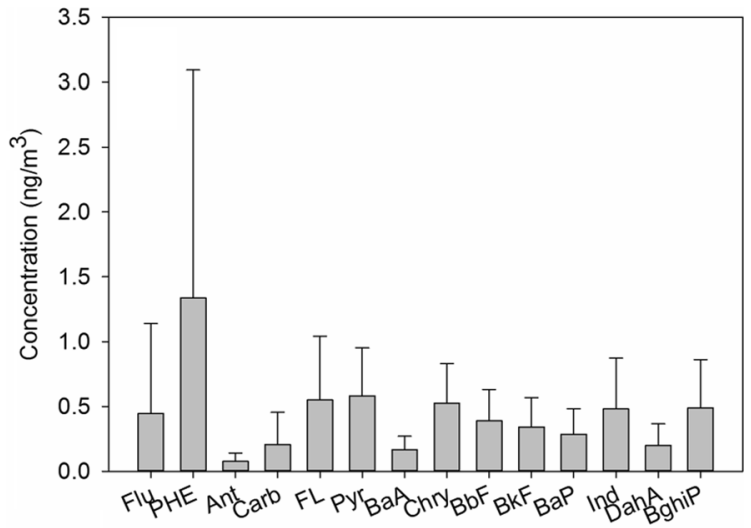

d

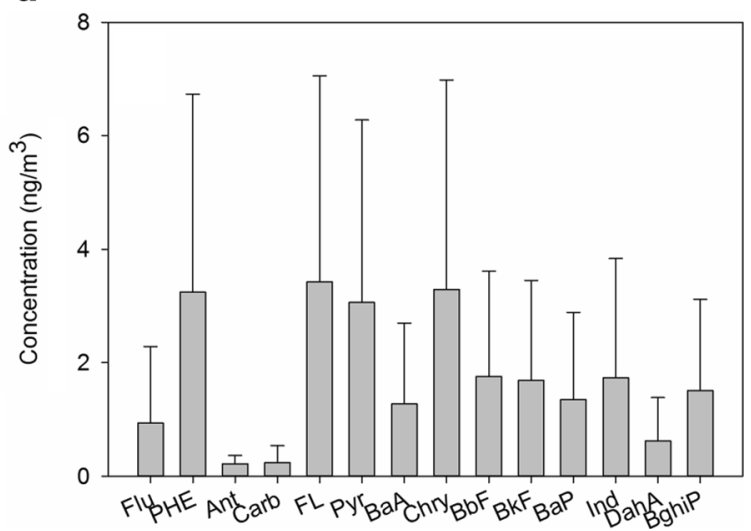

Fig. 3 Seasonal variation in the average PAH concentrations. a Gas phase in non-heating period. b Particle phase in non-heating period. $\mathbf{c}$ Gas phase in heating period. $\mathbf{d}$ Particle phase in heating period (error bars indicate one standard deviation)

TSP-bound BaP measured in this study $\left(0.7 \mathrm{ng} / \mathrm{m}^{3}\right)$ is less than the standard level.

\section{Exposure and risk assessment}

Monte Carlo simulation was implemented to estimate population exposure and risk distributions for inhalation and dermal exposure routes. Fitted distributions to model parameters are given in SM, Tables S4 and S5. The 95th percentile exposure to $\sum_{32} \mathrm{PCBs}$ was found as $1.83 \times 10^{-3}$ and $121 \mathrm{pg} / \mathrm{kg} /$ day for dermal and inhalation routes, respectively, which were translated into the 95 th percentile risks of $3.81 \times 10^{-12}$ and $2.49 \times 10^{-7}$, respectively. Ding et al. (2013) determined the highest inhalation exposure to $\sum_{25} \mathrm{PCBs}$ for adults as $8.69 \times 10^{-3}$ non-I-TEQ $\mathrm{pg} / \mathrm{kg} /$ day at a background area in Tianjin, China. The average exposure via inhalation route in this study was almost four orders of magnitude higher than the corresponding value in Tianjin, China. Overall, heating and non-heating period 95 th percentile risk levels associated with inhalation and dermal exposures for $\sum_{32} \mathrm{PCBs}$, OCPs, and $\sum_{14} \mathrm{PAHs}$ are given in Table 2 . The overall risks, ranked from high to low, were $\sum_{14} \mathrm{PAHs}, \sum_{32} \mathrm{PCBs}$, and $\sum_{7} \mathrm{OCPs}$. The 95 th percentile inhalation exposure and risk for individual OCPs ranged from 0.16 to $11.85 \mathrm{pg} / \mathrm{kg} /$ day, and from $1.38 \times 10^{-10}$ to $5.71 \times 10^{-8}$, respectively. The minimum and maximum levels were for $\gamma$-CHL and heptachlor, respectively. The 95th percentile dermal exposure and risk ranged from $5.30 \times 10^{-7}$ to $5.55 \times 10^{-4} \mathrm{pg} / \mathrm{kg} /$ day and from $1.86 \times 10^{-16}$ to $5.55 \times 10^{-13}$, respectively. The lowest level compound among OCPs was $\gamma$ CHL, whereas the highest was heptachlor. The 95th percentile exposure to $\sum_{14}$ PAHs was $0.90 \mathrm{ng} / \mathrm{kg} /$ day for inhalation and $1 \times 10^{-3} \mathrm{ng} / \mathrm{kg} / \mathrm{day}$ for dermal routes. The 95 th percentile inhalation and dermal risks for $\sum_{14} \mathrm{PAHs}$ are $4.07 \times 10^{-6}$ and $7.29 \times 10^{-9}$, respectively.

The risks are dominated by the PAHs with the highest in the heating period. Overall, the other addressed pollutants, led by PCBs, account for $\approx 10 \%$ of the risk $(\approx 20 \%$ in the non-heating period). Similarly, high PAH levels have been observed in Turkish cities in the recent years (Table 1). Therefore, significant decreasing trends can not be expected for PAHs in Turkey during the last decade. In Europe (EU-28), PAH levels have been declining from 1990 until $\approx 2002$ but were leveling off, even slightly increasing thereafter (EEA 2014). PCB levels in air are believed to slowly fall in all regions (except in the Arctic; Lammel and Stemmler 2012), which is confirmed for central Europe for 1997-2006 (Dvorská et al. 2009), but it could be regionally 
Table 2 Overall, heating, and non-heating period 95th percentile carcinogenic risks for inhalation and dermal exposure routes

\begin{tabular}{|c|c|c|c|c|c|c|}
\hline \multirow[b]{2}{*}{ Pollutant } & \multicolumn{3}{|l|}{ Inhalation } & \multicolumn{3}{|l|}{ Dermal } \\
\hline & Non-heating period & Heating period & Overall & Non-heating period & Heating period & Overall \\
\hline$\alpha-\mathrm{HCH}$ & $3.35 \times 10^{-8}$ & $1.29 \times 10^{-8}$ & $4.32 \times 10^{-8}$ & $1.66 \times 10^{-14}$ & $8.19 \times 10^{-15}$ & $2.06 \times 10^{-14}$ \\
\hline$\gamma-\mathrm{HCH}$ & $5.53 \times 10^{-9}$ & $3.95 \times 10^{-9}$ & $8.48 \times 10^{-9}$ & $7.02 \times 10^{-15}$ & $3.72 \times 10^{-15}$ & $8.95 \times 10^{-15}$ \\
\hline HEPCHL & $5.12 \times 10^{-8}$ & $1.28 \times 10^{-8}$ & $5.71 \times 10^{-8}$ & $4.91 \times 10^{-13}$ & $1.19 \times 10^{-13}$ & $5.55 \times 10^{-13}$ \\
\hline HEP EPOX & $1.02 \times 10^{-8}$ & $8.67 \times 10^{-9}$ & $1.71 \times 10^{-8}$ & $2.32 \times 10^{-14}$ & $1.17 \times 10^{-14}$ & $2.95 \times 10^{-14}$ \\
\hline$\gamma-\mathrm{CHL}$ & $1.15 \times 10^{-10}$ & $3.78 \times 10^{-11}$ & $1.38 \times 10^{-10}$ & $1.57 \times 10^{-16}$ & $5.61 \times 10^{-17}$ & $1.86 \times 10^{-16}$ \\
\hline$\alpha-\mathrm{CHL}$ & $1.60 \times 10^{-10}$ & $3.51 \times 10^{-11}$ & $1.78 \times 10^{-10}$ & - & - & - \\
\hline$p-p^{\prime}-\mathrm{DDT}$ & $1.04 \times 10^{-9}$ & $7.34 \times 10^{-10}$ & $1.54 \times 10^{-9}$ & $1.70 \times 10^{-13}$ & $4.49 \times 10^{-14}$ & $1.89 \times 10^{-13}$ \\
\hline${ }_{32} \mathrm{PCBs}$ & $1.81 \times 10^{-7}$ & $9.64 \times 10^{-8}$ & $2.49 \times 10^{-7}$ & $3.24 \times 10^{-12}$ & $9.52 \times 10^{-13}$ & $3.81 \times 10^{-12}$ \\
\hline${ }_{14} \mathrm{PAHs}$ & $9.08 \times 10^{-7}$ & $3.66 \times 10^{-6}$ & $4.07 \times 10^{-6}$ & $3.47 \times 10^{-9}$ & $5.92 \times 10^{-9}$ & $7.29 \times 10^{-9}$ \\
\hline
\end{tabular}

overcompensated by climate variability (mobilization from ground compartments triggered by higher temperatures; Lamon et al. 2009). The decision about the prohibition of PCB usage in Turkey was published in the official gazette in 1993, then entered into force in 1996 (RCHC 1993), but the long-term PCB trend in Turkey is not confirmed. However, PCB concentrations were measured in July 2012 at a rural/coastal site $\left(38^{\circ} 19^{\prime}\right.$ $\mathrm{N}, 26^{\circ} 38^{\prime} \mathrm{E}$ ) at the campus of Izmir Institute of Technology in Gulbahce, Urla, $\approx 50 \mathrm{~km}$ west (direct distance) of the sampling site (Lammel et al. 2015). Eleven daytime gas and particle-phase samples were collected and analyzed for indicator PCBs (PCB$28,-52,-101,-118,-138,-153$, and -180). The average total (gas and particle phases) concentration for the sum of the indicator PCBs ( $\Sigma_{\mathrm{i}} \mathrm{PCBs}$ ) was $97 \pm 50 \mathrm{pg} / \mathrm{m}^{3}$ (arithmetic mean \pm standard deviation). The corresponding $\Sigma_{\mathrm{i}} \mathrm{PCBs}$ concentration of samples collected in this study in Summer 2003 (July $(n=4)$ and August $(n=4)$ samples were compiled to have similar sample sizes) was $107 \pm 72 \mathrm{pg} / \mathrm{m}^{3}$. Obviously, there is no clear long-term downward trend in PCB levels. Moreover, lower levels at Gulbahce than at the suburban Izmir site in this study could be attributed to the rural/coastal character of Gulbahce, i.e., lower density of electrical utilities, open applications, and residential buildings, which are possible PCB sources (MoEF 2010). It can be concluded that PCB levels were not very different in 2012 from 2003 to 2004. This is further supported by a recent study investigating the historical variations of POPs using dated tree cores at 14 industrial and background sites in Izmir region (Odabasi et al. 2015) showing that PAH and PCB concentrations in tree ring samples (that are suggested to be representative of ambient air levels) were stable or slightly increasing during the period of 2001-2011. Therefore, the estimated risk levels associated with inhalation and dermal contact in this study for both PAHs and PCBs are probably reasonable estimates for the current levels, assuming the same values for the other variables (inhalation rate and body weight) in the exposure-risk model.

The ratios of non-heating/heating period for 95th percentile risk due to inhaled total PCBs and individual OCPs were found as 1.87 and $1.18-4.56$, while these ratios for dermal exposure were calculated as 3.52 and 1.89-4.12, respectively. An increase in ambient air temperature gives rise to volatilization from atmospheric particles, soil, water, and vegetation (Sofuoglu et al. 2001). Therefore, the main reason for the difference in carcinogenic risks between sampling periods is most probably related to the higher volatilization rates for PCBs and OCPs in the non-heating period. The exposed surface area in the non-heating period is $19.3 \%$ of the total human body whereas this percentage decreases to $6.7 \%$ in the heating period, which contributes to the seasonal differences in risks associated with dermal contact. An assessment of seasonal variation in carcinogenic risk for individual PCB congeners in Catalonia, Spain (Vilavert et al., 2014), showed that dermal contact and inhalation risks in spring and autumn of 2010 and 2011 were very similar. On the other hand, risk associated with dermal exposure to PAHs in the heating period was found 1.70-folds that of in the non-heating period in this study. The main reason for the difference between the periods was the estimated particle $\mathrm{BaP}_{\mathrm{eq}}$ concentrations, thus the detected particle-phase PAH concentrations. While the mean values of total $\mathrm{PAH}$ concentrations and $\mathrm{BaP}_{\mathrm{eq}}$ concentrations in the heating period were calculated as 12.8 and $2.3 \mathrm{ng} / \mathrm{m}^{3}$, lower levels were detected as $5.2 \mathrm{ng} / \mathrm{m}^{3}$ for total PAH concentrations and $0.84 \mathrm{ng} / \mathrm{m}^{3}$ for $\mathrm{BaP}_{\mathrm{eq}}$ concentrations in the nonheating period. The similar seasonal trend also occurred for inhalation exposure with the ratio of heating/non-heating period of 4.03. Wu et al. (2014) analyzed PAH samples collected from Quanzhou and Xiamen, Southeast China. The ratios of inhalation risk in winter to summer at three sampling sites ranged from 2.13 to 2.63 , whereas this ratio was 23.65 at a fourth site. The seasonal differences are most probably due to increased combustion emissions in heating period and meteorological conditions such as lower mixing height, sunlight intensity, and thermal- and photo-decomposition (Devi et al. 2013; Liu et al. 2014; Wu et al. 2014). Carcinogenic risks due to PAH exposures have been studied extensively compared to 
PCBs and OCPs. However, there have been only two reports from Turkey. Gaga et al. (2012) investigated ambient air PAH concentrations and seasonal differences in the estimated inhalation carcinogenic risks in Kocaeli, Turkey, one of the most industrialized regions in the country. Risks via inhalation route were estimated by using the unit risk approach. Results of the assessment showed that cancer risk in heating period $\left(2.92 \times 10^{-3}\right)$ was approximately two times higher than that in non-heating period $\left(1.15 \times 10^{-3}\right)$. Although risk levels were much higher in Kocaeli, heating to non-heating period ratio was lower than that of this study (2.54 vs. 4.03 ) which may indicate the effect of industrial emissions and the type of fuel used in residential heating and the industry.

Inhalation risk for $\sum_{32} \mathrm{PCBs}$, OCPs, and $\sum_{14} \mathrm{PAHs}$ was approximately $6,4-7$, and 3 orders of magnitude greater than dermal risk, respectively (Fig. 4). The lower risk levels for dermal exposure can be explained with involvement of only the particle-phase concentrations and low skin permeability. Risk associated with inhalation route was 1.83-4.20 times higher than the dermal route in Spain (Vilavert et al. 2014). The only study considering both of the exposure routes for

\section{a}

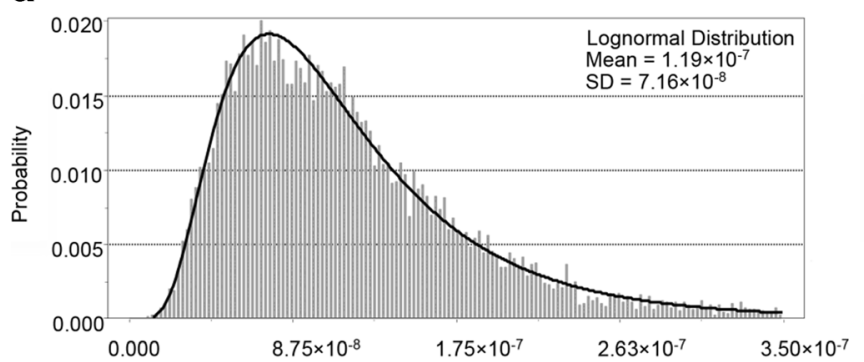

C

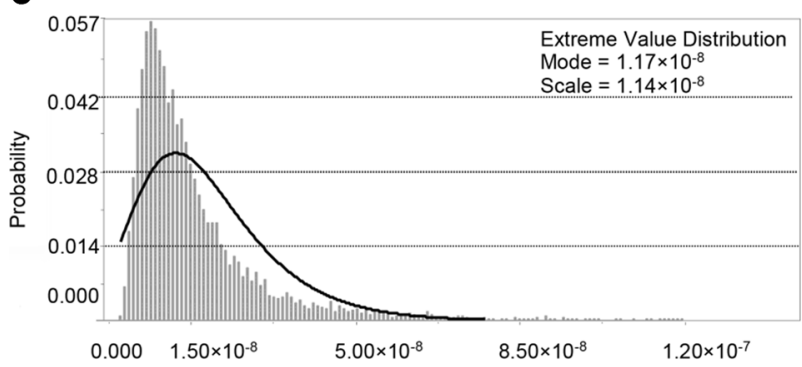

e

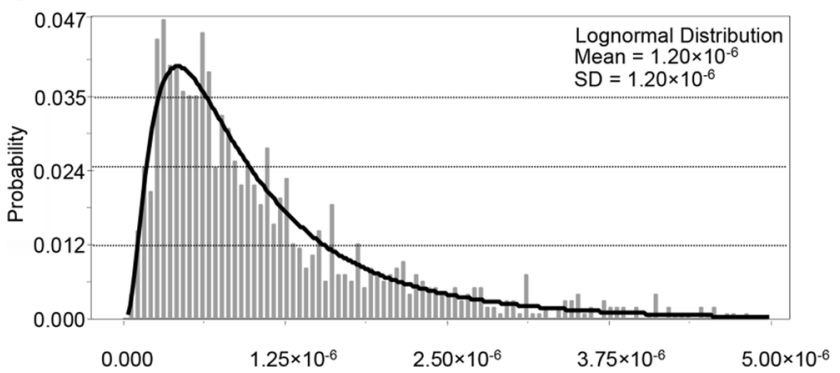

assessment in Turkey was conducted by Gungormus et al. (2014) in Balikesir, a relatively small city with a population of about 266,000 . The population risks associated with inhalation exposure ranged between $1.32 \times 10^{-7}$ and $2.23 \times 10^{-4}$ by using the same SF value used in this study. The dermal exposure was lower compared to those of inhalation, ranging from $6.58 \times 10^{-9}$ to $2.57 \times 10^{-6}$. Although Balikesir is a relatively small city, risk levels were higher than those of this study probably because their sampling site was urban while it was suburban in this study. The risks were also assessed for Taiwan, China (Chen and Liao 2006). The average risk for inhalation route $\left(1.04 \times 10^{-4}\right)$ was found as 2.70 times higher than dermal exposure $\left(3.85 \times 10^{-5}\right)$, a similar ratio to this study.

The acceptable carcinogenic risk may be different for different substances and countries, e.g., $10^{-4}-10^{-6}$ in the USA (USEPA 1991). However, $10^{-6}$ is considered as the general acceptable risk level for environmental pollutants. All the risk levels estimated in this study are lower than the general acceptable risk level except for PAHs. It should be, however, noted that results are based on ambient air concentrations

b

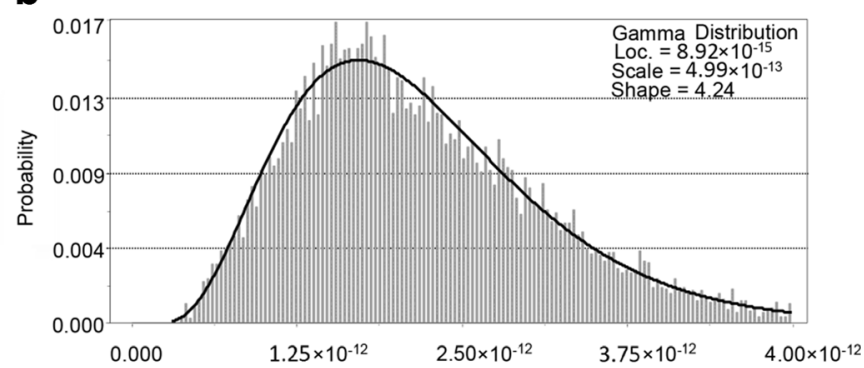

d

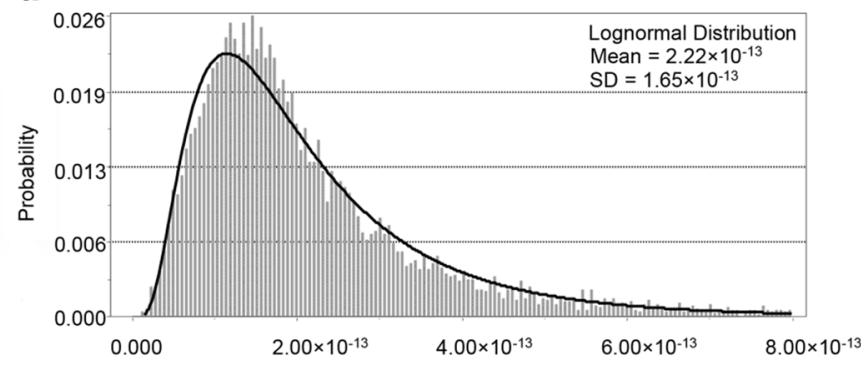

f

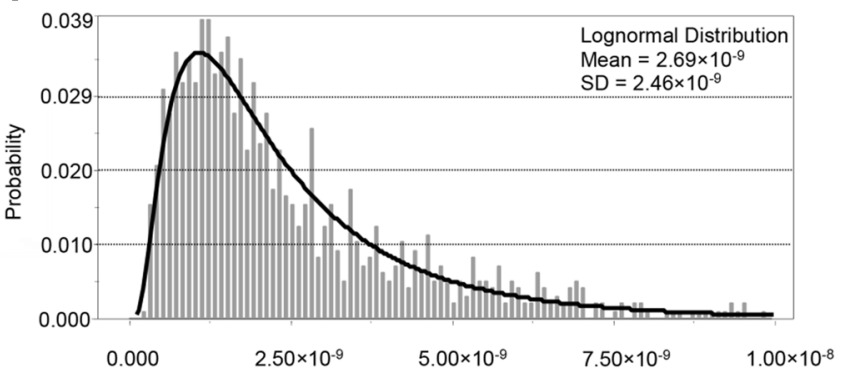

Fig. 4 Fitted probability distributions of carcinogenic risk associated with $\sum_{32} \mathrm{PCBs} \mathbf{a}$ inhalation and $\mathbf{b}$ dermal exposure, to heptachlor $\mathbf{c}$ inhalation and $\mathbf{d}$ dermal exposure, and $\sum_{14} \mathrm{PAHs} \mathbf{e}$ inhalation and $\mathbf{f}$ dermal exposure 
measured at a suburban site. Higher chronic exposure concentrations may occur in industrial regions, urban locations, and areas around waste disposal/destruction facilities (Hsu et al. 2003). The total PCB concentrations of $3370 \mathrm{pg} / \mathrm{m}^{3}$ (summer) and $1164 \mathrm{pg} / \mathrm{m}^{3}$ (winter) were measured at an industrial site in Aliaga industrial area near İzmir (Bozlaker et al. 2008), and $2119 \mathrm{pg} / \mathrm{m}^{3}$ (summer) and $1716 \mathrm{pg} / \mathrm{m}^{3}$ (winter) in urban İzmir, (Odabasi et al. 2008). In addition, indoor air concentrations may be higher than those of outdoors depending on the presence of indoor sources (Bohlin et al. 2008). Therefore, exposure and associated risk levels may be higher in those cases. Furthermore, POPs are ubiquitously found in house dust (Frederiksen et al. 2010). Children young enough to have hand-to-mouth behavior are additionally exposed compared to the rest of the population excluding people with high occupational exposures.

\section{Sensitivity and uncertainty analysis}

Sensitivity analysis was performed to determine the impact of input variables to the outputs (i.e., exposure and risk). Risk associated with dermal contact of PCBs mainly influenced from the particle-phase concentrations $(86.6 \%)$. The gasphase concentration of PCBs was the main influence with $42.9 \%$ for risk associated with inhalation. Due to having the highest risk levels, heptachlor was chosen as an example OCP for sensitivity analysis. Particle-phase heptachlor concentration was the dominant input variable for dermal risk with $85.7 \%$. Risk calculated for inhalation exposure was mostly affected from gas-phase heptachlor concentration with $47.6 \%$. The contribution of $\mathrm{BaP}_{\mathrm{eq}}$ concentration was the most significant variable with $69.6 \%$ for inhalation risk of PAHs. However, body weight was the most dominant input variable with the value of $99.2 \%$ for dermal risk.

Bootstrapping was implemented with 200 bootstrap samples and 1000 trials to analyze the uncertainties in the estimated carcinogenic risks. The results of the analysis are given in $\mathrm{SM}$, Table S6. Coefficient of variation values (CV) were $<7 \%$ for 5 th percentile for both of the exposure routes, and 95 th percentile of inhalation route for all of the pollutants. CV values for the mean and 50th percentile were $<4 \%$. CV was the largest (21.4\%) for 95th percentile risk of dermal exposure to $\mathrm{PCBs}$, indicating that uncertainties originating from the Monte Carlo simulation were low in general.

\section{Summary and conclusions}

Ambient air concentrations were measured for a year at a suburban site in Izmir, Turkey, and carcinogenic risks associated with inhalation and dermal exposure were estimated for 32 PCBs, 7 OCPs, and 14 PAHs from May 2003 to April 2004. Annual mean concentrations of $\sum_{32} \mathrm{PCBs}$ and $\sum_{14}$ PAHs were determined as $348 \pm 334 \mathrm{pg} / \mathrm{m}^{3}$ and $35.7 \pm 39.5 \mathrm{ng} / \mathrm{m}^{3}$, respectively. Endosulfan I was found at higher levels $\left(273.3 \pm 549.9 \mathrm{pg} / \mathrm{m}^{3}\right)$ than the other target OCPs probably due to being legally in use in the study period. Higher PCB and OCP concentrations were apparent in the non-heating period probably because of the volatilization of the pollutants at higher temperatures. Inverse behavior was observed for PAHs probably because residential heating is one of the main sources of PAH emissions during the heating season. Exposure and risks for inhalation route were higher than dermal route. The 95th percentile risk levels were below the acceptable level except for PAHs. Sensitivity analysis suggested that the gas and particle-phase POP concentrations are the main determinants in the exposure-risk estimation. Comparable PCB and PAH levels measured in this study to those recent ones measured in the region indicate that the risks associated with exposure to the addressed pollutants through inhalation and dermal routes are similar today, i.e., one decade after this study.

Acknowledgments This study was partly supported by the Scientific and Technical Research Council of Turkey (TUBITAK), Grant\# ICTAGC033, and Izmir Institute of Technology, Grant\# IYTE-BAP-20.

\section{Compliance with ethical standards}

Conflict of interest The authors declare no conflict of interest.

\section{References}

Akyüz M, Çabuk H (2010) Gas-particle partitioning and seasonal variation of polycyclic aromatic hydrocarbons in the atmosphere of Zonguldak, Turkey. Sci Total Environ 408:5550-5558

Birgül A, Taşdemir Y (2011) Seasonal atmospheric deposition variations of polychlorinated biphenyls (PCBs) and comparison of some deposition sampling techniques. Environ Sci Pollut Res 18:396-406

Birgül A, Taşdemir Y, Cindoruk SS (2011) Atmospheric wet and dry deposition of polycyclic aromatic hydrocarbons (PAHs) determined using a modified sampler. Atmos Res 101:341-353

Bohlin P, Jones KC, Tovalin H, Strandberg B (2008) Observations on persistent organic pollutants in indoor and outdoor air using passive polyurethane foam samplers. Atmos Environ 42:7234-7241

Bozlaker A, Muezzinoglu A, Odabasi M (2009) Processes affecting the movement of organochlorine pesticides (OCPs) between soil and air in an industrial site in Turkey. Chemosphere 77:1168-1176

Bozlaker A, Odabasi M, Muezzinoglu A (2008) Dry deposition and soilair gas exchange of polychlorinated biphenyls (PCBs) in an industrial area. Environ Pollut 156:784-793

Breivik K, Sweetman A, Pacyna JM, Jones KC (2002) Towards a global historical emission inventory for selected PCB congeners, a mass balance approach: I. Global production and consumption. Sci Total Environ 290:181-198

California Environmental Protection Agency (CalEPA) (2005) Air toxics hot spots program risk assessment guidelines - part 2: technical support document for describing available cancer potency factors, 
Office of Environmental Health Hazard Assessment, Oakland, CA, $662 \mathrm{pp}$

Castro-Jiménez J, Deviller G, Ghiani M, Loos R, Mariani G, Skejo H, Umlauf G, Wollgast J, Laugier T, Héas-Moisan K, Léauté F, Munschy C, Tixier C, Tronczyński J (2008) PCDD/F and PCB multi-media ambient concentrations, congener patterns and occurrence in a Mediterranean coastal lagoon (Etang de Thau, France). Environ Pollut 156:123-135

Cetin B, Yatkin S, Bayram A, Odabasi M (2007) Ambient concentrations and source apportionment of PCBs and trace elements around an industrial area in Izmir, Turkey. Chemosphere 69:1267-1277

Chen SC, Liao CM (2006) Health risk assessment on human exposed to environmental polycyclic aromatic hydrocarbons pollution sources. Sci Total Environ 366:112-123

Choi SD, Baek SY, Chang YS, Wania F, Ikonomou MG, Yoon YJ, Park BK, Hong S (2008) Passive air sampling of polychlorinated biphenyls and organochlorine pesticides at the Korean Arctic and Antarctic research stations: implications for long-range transport and local pollution. Environ Sci Technol 42:7125-7131

Demircioglu E, Sofuoglu A, Odabasi M (2011) Atmospheric concentrations and phase partitioning of polycyclic aromatic hydrocarbons in Izmir, Turkey. Clean-Soil, Air, Water 39:319-327

Devi NL, Shihua Q, Yadav IC (2013) Atmospheric polycyclic aromatic hydrocarbons (PAH) in Manipur of the Northeast India: monitoring on urban, rural, and mountain sites. Polycycl Aromat Compd 34:1234

Ding L, Li YM, Wang P, Li XM, Zhao ZS, Ruan T, Zhang QH (2013) Spatial concentration, congener profiles and inhalation risk assessment of PCDD/Fs and PCBs in the atmosphere of Tianjin, China. Chin Sci Bull 58:971-978

Dvorská A, Lammel G, Holoubek I (2009) Recent trends of persistent organic pollutants in air in Europe - air monitoring in combination with air mass trajectory statistics as a tool to study the effectivity of regional chemical policy. Atmos Environ 43:1280-1287

European Commission (EC) (2001) Ambient air pollution by polycyclic aromatic hydrocarbons (PAH) - position paper, Office for Official Publications of the European Communities, Luxembourg, 56 pp

European Environment Agency (EEA) (2014) European Union emission inventory report 1990-2012 under the UNECE Convention on longrange transboundary air pollution (CLRTAP) - technical report number 12, Copenhagen, $132 \mathrm{pp}$

Esen F, Cindoruk SS, Tasdemir Y (2006) Ambient concentrations and gas/particle partitioning of polycyclic aromatic hydrocarbons in an urban site in Turkey. Environ Forensic 7:303-312

Frederiksen M, Thomsen C, Frøshaug M, Vorkamp K, Thomsen M, Becher G, Knudsen LE (2010) Polybrominated diphenyl ethers in paired samples of maternal and umbilical cord blood plasma and associations with house dust in a Danish cohort. Int J Hyg Environ Health 213:233-242

Gaga EO, Ari A, Dogeroglu T, Cakirca EE, Machin NE (2012) Atmospheric polycyclic aromatic hydrocarbons in an industrialized city, Kocaeli, Turkey: study of seasonal variations, influence of meteorological parameters and health risk estimation. J Environ Monit 14:2219-2229

Gephart LA, Tell JG, Triemer LR (1994) Exposure factors manual. J Soil Contam 3:47-117

Gungormus E, Tuncel S, Tecer LH, Sofuoglu SC (2014) Inhalation and dermal exposure to atmospheric polycyclic aromatic hydrocarbons and associated carcinogenic risks in a relatively small city. Ecotoxicol Environ Saf 108:106-113

Halse AK, Schlabach M, Eckhardt S, Sweetman A, Jones KC, Breivik K (2011) Spatial variability of POPs in European background air. Atmos Chem Phys 11:1549-1564

Haugen JE, Wania F, Ritter N, Schlabach M (1998) Hexachlorocyclohexanes in air in southern Norway. Temporal variation, source allocation, and temperature dependence. Environ Sci Technol 32:217-224

He J, Fan S, Meng Q, Sun Y, Zhang J, Zu F (2014) Polycyclic aromatic hydrocarbons (PAHs) associated with fine particulate matters in Nanjing, China: distributions, sources and meteorological influences. Atmos Environ 89:207-215

Helsel DR (1990) Less than obvious - statistical treatment of data below the detection limit. Environ Sci Technol 24:1766-1774

Hogarth JN, Seike N, Kobara Y, Masunaga S (2012) Atmospheric polychlorinated naphthalenes in Ghana. Environ Sci Technol 46: 2600-2606

Holoubek I, Klánová J, Jarkovský J, Kohoutek J (2007) Trends in background levels of persistent organic pollutants at Košetice observatory, Czech Republic. Part I. Ambient air and wet deposition 19882005. J Environ Monit 9:557-563

Hsu YK, Holsen TM, Hopke PK (2003) Comparison of hybrid receptor models to locate PCB sources in Chicago. Atmos Environ 37:545562

Hung H, Kallenborn R, Breivik K, Su YS, Brorström-Lundén E, Olafsdottir K, Thorlacius JM, Leppänen S, Bossi R, Skov H, Manø S, Patton GW, Stern G, Sverko E, Fellin P (2010) Atmospheric monitoring of organic pollutants in the Arctic under the Arctic Monitoring and Assessment Programme (AMAP): 1993 2006. Sci Total Environ 408:2854-2873

International Agency for Research on Cancer (IARC) (2013) Polychlorinated biphenyls and polybrominated biphenyls, monographs Vol 107,Lyon, 510 pp

Integrated Risk Information System (IRIS) (2015) Slope factor values. http://www.epa.gov/iris. Accessed in 05 June 2015

Kavcar P, Odabasi M, Kitis M, Inal F, Sofuoglu SC (2006) Occurrence, oral exposure and risk assessment of volatile organic compounds in drinking water for İzmir. Water Res 40:3219-3230

Kaya E, Dumanoglu Y, Kara M, Altiok H, Bayram A, Elbir T, Odabasi M (2012) Spatial and temporal variation and air-soil exchange of atmospheric PAHs and PCBs in an industrial region. Atmos Pollut Res 3:435-449

Klánová J, Čupr P, Holoubek I, Borůvková J, Přibylová P, Kareš R, Tomšej T, Ocelka T (2009) Persistent organic pollutants in Africa. Part 1: passive air sampling across a continent-wide network 2008. J Environ Monit 11:1952-1963

Klánová J, Diamond ML, Jones KC, Lammel G, Lohmann R, Pirrone N, Scheringer M, et al. (2011) Identifying the research and infrastructure needs for the global assessment of hazardous chemicals 10 years after establishing the Stockholm convention. Environ Sci Technol 45:7617-7619

Lammel G, Stemmler I (2012) Fractionation and current time trends of PCB congeners: evolvement of distributions 1950-2010 studied using a global atmosphere-ocean general circulation model. Atmos Chem Phys 12:7199-7213

Lammel G, Audy O, Besis A, Efstathiou C, Eleftheriadis K, Kohoutek J, Kukučka P, Mulder MD, Přibylová P, Prokeš R, Rusina TP, Samara C, Sofuoglu A, Sofuoglu SC, Taşdemir Y, Vassilatou V, Voutsa D, Vrana B (2015) Air and seawater pollution and air-sea gas exchange of persistent toxic substances in the Aegean Sea: spatial trends of PAHs, PCBs, OCPs and PBDEs. Environ Sci Pollut Res 22:1130111313

Lamon L, von Waldow H, MacLeod M, Scheringer M, Marcomini A, Hungerbühler K (2009) Modeling the global levels and distribution of polychlorinated biphenyls in air under a climate change scenario. Environ Sci Technol 43:5818-5824

Li QQ, Loganath A, Seng Chong Y, Tan J, Philip Obbard J (2006) Persistent organic pollutants and adverse health effects in humans. J Toxicol Environ Health, Part A 69:1987-2005

Liu D, Xu Y, Chaemfa C, Tian CG, Li J, Luo CL, Zhang G (2014) Concentrations, seasonal variations, and outflow of atmospheric 
polycyclic aromatic hydrocarbons (PAHs) at Ningbo site, eastern China. Atmos Pollut Res 5:203-209

Livingston EH, Lee S (2001) Body surface area prediction in normalweight and obese patients. Am J Physiol-Endocrinol Metab 281: E586-E591

Lohmann R, Breivik K, Dachs J, Muir D (2007) Global fate of POPs: current and future research directions. Environ Pollut 150:150-165

Ministry of Environment and Forestry (MoEF) (2010) National implementation plan for the Stockholm convention on persistent organic pollutants, Ankara $240 \mathrm{pp}$

Ministry of Environment and Urbanization (MoEU) (2015) National implementation plan of persistent organic pollutants (POPs) management in Turkey, Ankara, $74+333$ pp

Odabasi M, Ozgunerge Falay E, Tuna G, Altiok H, Kara M, Dumanoglu Y, Bayram A, Tolunay D, Elbir T (2015) Biomonitoring the spatial and historical variations of persistent organic pollutants (POPs) in an industrial region. Environ Sci Technol 49:2105-2114

Odabasi M, Cetin B (2012) Determination of octanol-air partition coefficients of organochlorine pesticides (OCPs) as a function of temperature: application to air-soil exchange. J Environ Manag 113:432-439

Odabasi M, Cetin B, Demircioglu E, Sofuoglu A (2008) Air-water exchange of polychlorinated biphenyls (PCBs) and organochlorine pesticides (OCPs) at a coastal site in Izmir Bay, Turkey. Mar Chem 109:115-129

Offical Gazette (2008) Ambient air quality assessment and management regulation: official gazette number 26898. Issued on June 2008

Ozcan S, Aydin ME (2009) Polycyclic aromatic hydrocarbons, polychlorinated biphenyls and organochlorine pesticides in urban air of Konya, Turkey. Atmos Res 93:715-722

Pozo K, Harner T, Wania F, Muir DCG, Jones KC, Barrie LA (2006) Toward a global network for persistent organic pollutants in air: results from the GAPS study. Environ Sci Technol 40:4867-4873

Pozo K, Harner T, Lee SC, Wania F, Muir DCG, Jones KC (2009) Seasonally resolved concentrations of persistent organic pollutants in the global atmosphere from the first year of the GAPS study. Environ Sci Technol 43:796-803

Pozo K, Harner T, Rudolph A, Oyola G, Estellano VH, AhumadaRudolph R, Garrido M, Pozo K, Mabilia R, Focardi S (2012) Survey of persistent organic pollutants (POPs) and polycyclic aromatic hydrocarbons (PAHs) in the atmosphere of rural, urban and industrial areas of Concepcion, Chile, using passive air samplers. Atmos Pollut Res 3:426-434

The Risk Assessment Information System (RAIS) (2013) Gastrointestinal adsorption factors and skin permeability constants. http://rais.ornl. gov. Accessed in 07 July 2015

RCHC (1993) Regulation for the control of hazardous chemicals: official gazette number 21634. Issued on July 1993

Sofuoglu A, Cetin E, Bozacioglu SS, Sener GD, Odabasi M (2004) Shortterm variation in ambient concentrations and gas/particle partitioning of organochlorine pesticides in Izmir, Turkey. Atmos Environ 38:4483-4493

Sofuoglu A, Odabasi M, Tasdemir Y, Khalili NR, Holsen TM (2001) Temperature dependence of gas-phase polycyclic aromatic hydrocarbon and organochlorine pesticide concentrations in Chicago air. Atmos Environ 35:6503-6510

Stafilov T, Škrbić B, Klánová J, Čupr P, Holoubek I, Kočov M, ĐurišićMladenović N (2011) Chemometric assessment of the semivolatile organic contaminants content in the atmosphere of the selected sites in the Republic of Macedonia. J Chemometr 25:262-274

Stern GA, Halsall CJ, Barrie LA, Muir DCG, Fellin P, Rosenberg B, Rovinsky FY, Kononov EY, Pastuhov B (1997) Polychlorinated biphenyls in Arctic air.1. Temporal and spatial trends: 1992-1994. Environ Sci Technol 31:3619-3628

Tașdemir Y, Esen F (2007) Urban air PAHs: concentrations, temporal changes and gas/particle partitioning at a traffic site in Turkey. Atmos Res 84:1-12

Terzi E, Samara C (2004) Gas-particle partitioning of polycyclic aromatic hydrocarbons in urban, adjacent coastal, and continental background sites of western Greece. Environ Sci Technol 8:4973-4978

Turkish Statistical Institute (TUIK) (2013) Address based population registration system census. Ankara, Turkey

United Nation Environment Programm (UNEP) (2013) Results of the global survey on concentrations in human milk of persistent organic pollutants by the United Nations Environment Programme and the World Health Organization. Geneva, $42 \mathrm{pp}$

U.S. Environmental Protection Agency (USEPA) (1991) Risk assessment guidance for superfund volume I: human health evaluation manual (Part B, Development of risk-based preliminary remediation goals). Washington, DC, $63 \mathrm{pp}$

U.S. Environmental Protection Agency (USEPA) (1992a) Risk assessment guidelines for exposure assessment. Washington, DC, $139 \mathrm{pp}$

U.S. Environmental Protection Agency (USEPA) (1992b) Dermal exposure assessment: principles and applications. Office of Health and Environmental Assessment, Washington, DC, 389 pp

U.S. Environmental Protection Agency (USEPA) (1997) Health effects assessment summary tables, FY 1997 update. Environmental Criteria and Assessment Office, Office of Health and Environmental Assessment, Office of Research and Development, Cincinnati, OH, 404 pp

U.S. Environmental Protection Agency (USEPA) (2010) Recommended toxicity equivalence factors (TEFs) for human health risk assessments of 2,3,7,8-tetrachlorodibenzo-p-dioxin and dioxin-like compounds. Risk Assessment Forum, Washington, DC, 38 pp

Vasilakos C, Levi N, Maggos T, Hatzianestis J, Michopoulos J, Helmis C (2007) Gas-particle concentration and characterization of sources of PAHs in the atmosphere of a suburban area in Athens, Greece. J Hazard Mater 140:45-51

Vilavert L, Nadal M, Schuhmacher M, Domingo JL (2014) Seasonal surveillance of airborne PCDD/fs, PCBs and PCNs using passive samplers to assess human health risks. Sci Total Environ 466-467: 733-740

Wick AF, Haus NW, Sukkariyah BF, Haering KC, Daniels WL (2011) Remediation of PAH-contaminated soils and sediments: a literature review. CSES Department, Internal Research Document, 102

Wu SP, Yang BY, Wang XH, Yuan CS, Hong HS (2014) Polycyclic aromatic hydrocarbons in the atmosphere of two subtropical cities in Southeast China: seasonal variation and gas/particle partitioning. Aerosol Air Qual Res 14:1232-1246

Yenisoy-Karakas S, Oz M, Gaga EO (2012) Seasonal variation, sources, and gas/particle concentrations of PCBs and OCPs at high altitude suburban site in western Black Sea region of Turkey. J Environ Monit 14:1365-1374

Yolsal D, Salihoglu G, Taşdemir Y (2014) Air-soil exchange of PCBs: levels and temporal variations at two sites in Turkey. Environ Sci Pollut Res 21:3920-3935

Zhang LF, Dong L, Yang WL, Zhou L, Shi SX, Zhang XL, Niu S, Li LL, Wu ZX, Huang YR (2013) Passive air sampling of organochlorine pesticides and polychlorinated biphenyls in the Yangtze River Delta, China: concentrations, distributions, and cancer risk assessment. Environ Pollut 181:159-166 